\title{
Solving math and science problems in the real world with a computational mind
}

\author{
Juan Carlos Olabe ${ }^{1}$, Xabier Basogain 2,*, Miguel Ángel Olabe ${ }^{3}$, Inmaculada Maíz ${ }^{4}$, \\ Carlos Castaño ${ }^{5}$ \\ 1Department of Systems and Automatic Engineering, Christian Brothers University, U.S. \{jolabe@cbu.edu\} \\ ${ }^{2}$ Department of Communications Engineering, University of the Basque Country, Spain \\ \{xabier.basogain@ehu.es\} \\ ${ }^{3}$ Department of Communications Engineering, University of the Basque Country, Spain \\ \{miguelangel.olabe@ehu.es\} \\ ${ }^{4}$ Department of Evolutionary Psychology, University of the Basque Country, Spain \{inmaculada.maiz \\ @ehu.es\} \\ ${ }^{5}$ Department of Didactic Organization, University of the Basque Country, Spain \{carlos.castano@ehu.es\} \\ Received on 27 May 2013; revised on 16 September 2013; accepted on 20 September 2013; published on 15 July 2014
}

DOI: 10.7821/naer.3.2.75-82

\begin{abstract}
This article presents a new paradigm for the study of Math and Sciences curriculum during primary and secondary education. A workshop for Education undergraduates at four different campuses $(n=242)$ was designed to introduce participants to the new paradigm. In order to make a qualitative analysis of the current school methodologies in mathematics, participants were introduced to a taxonomic tool for the description of K-12 Math problems. The tool allows the identification, decomposition and description of Type-A problems, the characteristic ones in the traditional curriculum, and of Type-B problems in the new paradigm. The workshops culminated with a set of surveys where participants were asked to assess both the current and the new proposed paradigms. The surveys in this study revealed that according to the majority of participants: (i) The K-12 Mathematics curricula are designed to teach students exclusively the resolution of Type-A problems; (ii) real life Math problems respond to a paradigm of Type-B problems; and (iii) the current Math curriculum should be modified to include this new paradigm.
\end{abstract}

KEYWORDS: MATHEMATICS CURRICULUM, PROBLEM SOLVING, PROGRAMMING, INTELLIGENCE TESTS, EDUCATIONAL RESEARCH

\section{INTRODUCTION}

The way of thinking generally associated by psychologists with the areas of sciences and mathematics is referred to as 'analytical thinking' (Carpenter, Just \& Shell, 1990). Analytical thinking provides resources both to deal with novelty and to adapt to new cognitive problems. It includes the ability to reason and solve new problems, without depending exclusively on information learned at school (Cattell, 1963).

*To whom correspondence should be addressed:

Escuela Técnica Superior de Ingeniería de Bilbao

C/ Alameda Urquijo s/n

48013-Bilbao
The Raven Progressive Matrices Test (Raven, 1962) provides an appropriate environment to study and assess the characteristics of analytical intelligence, as well as the underlying general processes involved (Jensen, 1987; Snow, Kyllonen \& Marshalek, 1984). This test is considered to be at the core of the complexity in the large cluster of cognitive tests (Marshalek, Lohman \& Snow, 1983). The 36 problems in the test require a three-step sequential process to be solved. The difficulty of each problem is determined by the type and number of rules incorporated into it.

The current system for mathematics and science education used throughout the developed world (Pisa, 2009) is designed to foster the set of skills required to solve this type of three-step sequential problems.

Significant developments have occurred in the area of Cognitive Sciences during the last four decades (Ariely, 2009; Fiske, Gilbert \& Lindzey, 2010; Kahneman, 2003; Schwartz, 2005) which are providing a clearer picture of the capacities, limitations, biases and tendencies of the human mind. The area of Computer Engineering has simultaneously developed tools, in particular languages and paradigms based on languages and objects that have revolutionized the way in which the mind addresses the tasks of thinking, creating and solving problems (DiSessa, 2000; National Research Council, 2010, 2011; Papert, 1981, 1990; Royal Society, 2012; Wing, 2006)

On the whole, the Educational Systems applied in developed countries are large complex systems, slow to evolve, and have not yet incorporated the fundamental discoveries in the fields of cognitive sciences and computer engineering into their curricular or pedagogical paradigms (Collins \& Halverson, 2009).

This paper presents a research approach where undergraduate students of Education are introduced to some of these ideas, and then are asked to perform tasks of evaluation, curriculum assessment, and curriculum design.

One of the aims of this work is to design a set of experiences that will promote and build a solid dialog infrastructure between 
the worlds of Cognitive and Computational sciences and the world of Education so as to facilitate communication of ideas, curricular and pedagogical collaboration.

Illustrative examples of how such dialog infrastructure could be built are the workshops described in this article, along with the initiatives proposed in their aftermath. A total of 242 Education undergraduates had the chance to analyze and adopt new and fundamental ideas on education developed in the areas of Cognitive and Computational sciences in recent decades. In the short period of time during which the workshop took place, participants were able to personally explore these ideas by constructing computer-based projects, and also to experience the cognitive processes presented by the new paradigm. As a result of these workshops, some initiatives have been undertaken by Schools of Education to: 1) continue the development of similar workshops and the exchange of ideas; 2) the formal integration of topics related to these new paradigms into the curriculum of Schools of Education; and 3) the creation of new content and curriculum in K-12 Mathematics.

\section{BACKGROUND}

Several standardized tests (Becker, 2003; Binet \& Simon, 1916; Wechsler, 1939, 2005) have been used to determine a score, intelligence quotient or IQ, as a measure or assessment of intelligence, for over a century. The Raven Progressive Matrices Test includes a set of 36 problems with a similar format and an increasing level of difficulty. In one study (Forbes, 1964), a total of 2,256 British adults were tested, the results showing an almost perfect linear relationship between the number of each question and the percentage of adults who answered that question correctly: questions 1,2 , for example, were correctly answered by most participants, while questions 34, 35, and 36 were correctly answered by only a very small proportion of participants. This test was consequently designed to discriminate the location of any participant on the IQ scale with high accuracy.

Although the format is the same in all 36 questions, their difficulty is determined by the number and type of rules incorporated into the problem. Questions 1 and 2 include only two simple rules, while questions 34,35 , and 36 include four or five difficult rules.

Given the taxonomy of rules and their number in the set of 36 questions, it is possible to describe the scope of human intelligence in these terms (number and type of rules); from the IQ required to solve a simple problem that all humans are able to solve to the IQ required to solve a difficult problem that only few humans can solve.

Each problem consists of images grouped in a matrix with three rows and three columns, where the cell of the right column and bottom row is empty. The participant has to select the missing image from a selection of six choices. The images on each row are related to each other through some type of rule. The same applies to the relationship between the images in each column.

The problem-solving process includes three steps: Correspondence; Rule identification; and Rule application. Correspondence involves finding which elements of the images are relevant and which ones are superfluous. Rule identification has as its aim to discover the different rules which relate these elements. And, finally, Rule application seeks to apply these rules to the images present in the matrix as a way to deduce the characteristics of the missing image.
A detailed analysis of the types of math problems studied and practiced throughout the school years by students around the world would reveal that they share the same structure, which in turn has the same characteristics as the Raven problems. Standardized tests, such as those of the Programme for International Student Assessment (PISA), or university entry tests such as the American College Testing (ACT) Test or the Scholastic Assessment Test (SAT) (ACT, 2013; SAT, 2013) are good resources to investigate this structure. These problems will be referred to as Type-A problems here.

\subsection{Type-A Problems}

The three phases to solve these problems are also: Correspondence; Rule identification; and Rule application.

An example from the PISA exam: "An attic floor has a square shape with 12-meter sides. What is the area of the attic floor?”

The correspondence phase consists in finding the relevant data in the problem, which data is important and what is being asked. In this case, it is important to know that the floor has a square shape and its sides are 12 meters long. It is also important to notice that they ask us to calculate the floor area. These three pieces of information (square, 12, area) are the result of the correspondence phase.

Rule identification is the stage used to determine what rules relate those things that we know and those that we do not know. The area must be found in this case, and it is known to us that the shape is a square; therefore only one rule is needed, namely the relationship between area and side for a square. The rule is Area $=$ side $*$ side.

As for rule application, it consists in substituting the known data into the rule or rules and determining the solution for the problem. Area $=$ side $*$ side; Area $=12 * 12$; Area $=144$. Comparing this example with the Raven problems would lead us to rank its complexity as low: it requires only one rule, and the rule is simple.

In another example, this time from the ACT (American College Testing) math test, the problem is: "A car averages 27 miles per gallon. If gas costs $\$ 4.04$ per gallon, calculate the cost for this car to travel 2,727 typical miles." With the same taxonomic analysis, this problem is more difficult because there are more correspondence elements (27 miles/gallon, 4.04 dollars/gallon, 2,727 miles, total cost) and more rules (cost= gallons *dollars/gallon; gallons = miles $/$ \{miles/gallon $\}$ ).

Type-A problems such as these present a number of essential properties: they are deterministic in their solution (the solution is known and unique); and they are deterministic in process (the path to the solution is known and unique too). They are ideal for standardized tests, given their deterministic solutions.

They are equally ideal for standardized teaching. Phase three of the process, rule application, requires using arithmetic and often simple algebra. Phase two, rule identification, extends the area of knowledge and scope of problems taught in the classroom by taking advantage of the underlying three-phase process of Type-A problems: adding new rules extends the curriculum.

Most students understand why the area of a square is the product of the side by itself; not everyone can articulate why the area of any triangle is half the product of the base and the height; and almost no one knows why the area of a circle is $\pi$ times the radius * radius, or why the kinetic energy of a body is one half the product of the mass and the square of the velocity.

The three-phase paradigm, Type-A problems, allows an Education System to teach a wide variety of subjects, and when it is successful, it produces educated citizens that will calculate 
areas of squares and circles correctly, regardless of whether they understand or not why their calculations are correct (Bälter, Enström \& Klingenberg, 2013; Taylor \& Rohrer, 2010).

\subsection{Type-B Problems}

The three-phase paradigm fails to address another more important and prevalent type of problem which is referred to as Type-B problems in our study. This is the type of problem which is normally found in everyday life and responds to a very different paradigm. Type-B problems have very different characteristics: they are non-deterministic in their solution (there is no single and a priori known solution); and they are nondeterministic in process (there is no single and a priori known path to these multiple solutions). The paths towards solutions are iterative in nature, and they require interaction with their environment. More importantly, based only on the number and type of rules, Type-B problems surpass the complexity of the most difficult Raven problems.

Type-B problems require higher level mental processes (as opposed to arithmetic or algebraic processes which can be implemented by a mechanical machine such as a cash register using gears).

An example of a Type-B problem that illustrates its differences with Type-A problems is the following problem taken from the area of cybernetics or self-regulated systems. This problem is introduced to sixth grade students (12 years of age). "Create and animate a butterfly that has only the ability to fly and to detect collision with walls. The butterfly lives inside a greenhouse divided into 16 rooms. All rooms are connected to the adjacent rooms via open doors". The butterfly must be able to traverse all 16 rooms in the greenhouse. This problem has multiple solutions, many of which are suboptimal, and many as well, quasi-optimal. Calculating the area of a circle -a Type-A problem- has only one solution, and the solution is known before the student faces the problem. In the case of the butterfly problem -a Type-B problem- there are infinite solutions, most of which are still unknown. In the problem of calculating the area of a circle, its resolution process is deterministic; it is specific and well known, even before the student attempts its resolution. Instead, the butterfly problem has multiple strategies for its resolution, and all require and iterative process, where the next step can only be decided after examining the outcomes of the current step. There is no predefined and known path for its complete resolution. A Type-A problem such as the calculation of the area of a circle is deterministic in its solution and in the process that leads to finding it. A Type-B problem is nondeterministic in its solution and in the process which leads to find that solution. In addition, Type-B problems are iterative in their nature, and they require experimentation for their resolution.

The developments during the last four decades in the areas of cognitive sciences and computer engineering are providing paradigms, particularly those based on languages and objects that have revolutionized the way in which the mind addresses the tasks of thinking, creating and solving problems.

Graphic programming environments such as Alice, Greenfoot and Scratch (Utting, Cooper, Kolling, Maloney \& Resnick, 2010) are designed to introduce and develop programming and computational concepts using the fundamental ideas of objectbased languages. These programming environments are primarily intended for children and pre-college students. They are interactive applications where students have the chance to experiment and explore via program implementation. Such graphic programs provide visual environments where students can manipulate and see the effect of their actions and instructions on the screen in a direct and straightforward manner. The actions created in these environments occur between entities called objects that are characterized by their states, their behaviors, and their interactions with other objects. The conceptual integration of objects and their graphic representation provide these graphic environments with optimal pedagogical value.

Scratch and Snap (Maloney, Resnick, Rusk, Silverman \& Eastmond, 2010; Scratch, 2013; Snap, 2013) are two programming environments that allow for an easy prototyping of environments where one can experiment with the processes of solving Type-B problems. They could be simple problems, such as storytelling, or others of great mathematical sophistication, in areas such as dynamics, differential vector geometry, cybernetics, probabilistic analysis, or differential and integral calculus.

\section{METHOD}

The purpose of this research was to create a set of experiences, in the format of workshops, where students of education were introduced to the concepts of these two types of problems, and had the opportunity to experiment with them in order to reflect on the state of the current curriculum in mathematics. These experiences provided the foundation from which an assessment was made on topics such as: when do Type-A and Type-B problems appear in daily life?; when do they appear in the current educational systems?; how appropriate is it to prepare our young students to deal with them?; is it possible and recommended that the curriculum be updated to incorporate these paradigms?; and if that is the case, in what courses?.

The following sections describe the method for the creation of these experiences. The first section, Participants, describes the number, type and origin of the participants involved in the workshop. The following section, Structure, describes the structure and different types of activities implemented during the workshop. And the last section, Procedure, shows the characteristics and details of the procedure used for the implementation of the workshop at the four different university campuses.

\subsection{Participants}

A group of activities was designed from those developed during the 2012-13 academic year in the classrooms of several Schools of Education. The three participating Universities in these activities are: University of the Basque Country, University of Alicante, and University of Extremadura.

A total of four student groups took part in the workshop; they were identified as follows: EHU-1, UA, UEX and EHU-2. These groups have the characteristics listed below:

- EHU-1: Students of the University of the Basque Country, Leioa campus. Course Name: Information and Communication Technologies in Primary Education. Students in 2nd year of Primary Education Studies. Total: 21 students.

- EHU-2: Students of the University of the Basque Country, Gazteiz campus. Course Name: Didactics in Mathematics I. Students in 1st year of Primary Education Studies. Total: 9 students. 
- UA: Students of the University of Alicante. Course Name: Curricular Development and Digital Classrooms in Child Education. Students in 2nd year of Primary Education Studies. Total: 73 students divided into three working subgroups.

- UEX: Students of the University of Extremadura. Course Name: Didactic and Technologic Resources. Students in 1st year of Primary Education Studies. Total: 139 students divided into three working subgroups.

The participating students were freshmen and sophomores in Schools of Education, and ranged between 19 to 21 years of age. Female students represented a majority in all four groups.

Before embarking upon the experiences with these four groups, a pilot project was implemented with a group of 26 students of the University of the Basque Country during the 2011-12 academic year (Basogain, Olabe, Olabe, Maiz and Castaño, 2012). The experience and evaluation of the results obtained in this pilot project served to improve some design parameters for the present research.

\subsection{Structure}

The implemented experience was meant to introduce the students to a space of analysis and reflection on the topic of mathematics' education as it is presently implemented in today's school curriculum. In particular, the taxonomy of Type-A and Type-B problems was introduced, to which was added the incorporation of the graphic programming environments Scratch/Snap.

The experience is structured into four parts: introduction to Type-A problems; introduction to Type-B problems; introduction to Scratch/Snap; and a final survey. Each of the first three parts was implemented with the same format: description of the fundamental concepts; study of examples; and implementation of a group activity.

There were three group activities: resolution of a Type-A problem; definition of a Type-B problem; and implementation of a Scratch project. The first group activity consisted in the resolution of a problem from a choice of five different Type-A problems (one $4^{\text {th }}$ grade problem, one $5^{\text {th }}$ grade problem, one $6^{\text {th }}$ grade problem, and two problems from the PISA-2009 test in mathematics). The second group activity consisted in the creation and definition of a domestic event or situation of a student that included the characteristics of a Type-B problem. Finally, the third group activity consisted in the descriptive analysis of a Scratch project selected from a set of six basic projects using computational terminology.

The fourth activity included the completion of a final survey. Students answered a set of questions designed to evaluate fundamental aspects of mathematical education in the school system as well as the nature of school-type and real-life type problems. There were 9 multiple choice questions, organized according to the subject research areas. The survey also included a field to add optional comments if the student so desired.

These activities were performed in classrooms equipped with computer resources. Students implemented both group activities and individual surveys using these infrastructures: they experienced hands-on and participatory activities.

Additionally, a set of short personal interviews with the professors of the courses were carried out to collect qualitative data regarding the experience and those aspects that had not been covered in the survey's multiple choice questions.

\subsection{Procedure}

The experiences were implemented within the framework of a workshop entitled "Mathematical Experiences." The workshop developed at the four campuses of the three aforementioned Universities, with the groups labeled EHU-1, UA, UEX and EHU-2.

The workshops were conducted by a research team member in collaboration with the instructors of the corresponding courses at each campus. Sessions took place in multimedia classrooms equipped with audiovisual systems and internet access.

The workshops followed a four-part structure once again: introduction to Type-A problems; introduction to Type-B problems; introduction to Scratch/Snap; and a final survey. During the first three parts, the instructor combined the description of fundamental concepts with group and individual activities carried out by students.

Group activities were organized with participants collaborating in groups of 2 or 3 students. The first group activity was the resolution of a Type-A problem. The groups received the description of the problem and a form with the fields: Correspondence, Rule Identification and Rule Application. At the end of the activity, a spokesperson for each group described both the problem and its corresponding resolution process to the rest of the class.

The second group activity included the definition and description of a Type-B problem, and its resolution according to the proposed iterative methodology. Each group received a form with the fields that they had to complete: problem statement, and corresponding iterative steps. At the end of the activity, the same as in the previous activity, a representative of the group described both the problem statement and its resolution to the rest of the class.

The third group activity consisted in the description of a Scratch project through an interpretation of the meaning and interrelation of its programming blocks. Each group received a form with the graphic representation of the programming blocks in a project and also with fields to be completed by students with the analytical description of the project. At the end of the activity, a spokesperson for each group described both the block diagrams and their interpretation of the project to the rest of the class.

The group activities took 5 minutes for their resolution and 5 more minutes for sharing the result with the class.

The last part of the workshop was the implementation of the final survey. Students answered a total of 9 multiple choice questions; they summarized their experience during the workshop in these answers. The survey was implemented with a Google Drive questionnaire. The results of the survey will be described in the next section.

The duration of the workshop was adjusted to the available class time at each University and campus. Groups EHU-1 and EHU-2 participated in three 75-minute sessions during a period of three weeks (one session per week). The UA subgroups participated in a single 2-hour session. And the UEX subgroups only took part in one 90-minute-long session conducted via video-conference.

\section{RESULTS}

This section presents the results obtained in the proposed experience. The first section, Study, presents the responses of the participants to the questions included in the workshop's survey. The results indicate that a majority of participants have analyzed and understood the fundamental ideas of the paradigm 
introduced in the workshop. The last section, Comments and Interviews, presents personal experiences of students and professors involved in the workshop.

\subsection{Survey}

The purpose of the study implemented in this experience is to create an active environment for the analysis of new educational paradigms in the area of mathematics. The survey at the end of the workshop was designed to evaluate the degree to which this active environment is effective in the tasks of analyzing new paradigms, the evaluation of their characteristics, and the generation of required actions when these were identified. The absolute values as well as percentiles with the corresponding error margins will be used to validate the present study.

The descriptive statistics of this study presents the results for each of the four participant groups (EHU-1, UA, UEX, EHU-2) in numeric form collected in tables. These tables include the absolute values and their corresponding percentiles for each of the nine questions of the survey. The study has a sample size of 242 participants. The maximum margin of error is $6.3 \%$ for a level of confidence of $95 \%$. In those cases where $90 \%$ or more participants agreed (most tables), the margin of error is $4 \%$ or lower.

\subsubsection{Two types of Problems}

Table 1 shows the summary of views on the existence of two fundamental and different types of problems in everyday life: Type-A and Type-B problems. A total of 231 participants (95\%) thought that both types were present in daily life, while 7 participants (3\%) did not think so.

Table 1. Two types of Problems

\begin{tabular}{lrlllrlllrl}
\hline Option & \multicolumn{2}{c}{ EHU-1 } & \multicolumn{2}{c}{ UA } & \multicolumn{2}{c}{ UEX } & \multicolumn{2}{c}{ EHU-2 } & \multicolumn{2}{c}{ Total } \\
\hline Yes & 21 & $100 \%$ & 70 & $96 \%$ & 131 & $94 \%$ & 9 & $100 \%$ & 231 & $95 \%$ \\
No & 0 & $0 \%$ & 2 & $10 \%$ & 5 & $4 \%$ & 0 & $0 \%$ & 7 & $3 \%$ \\
I don't & 0 & $0 \%$ & 1 & $5 \%$ & 3 & $2 \%$ & 0 & $0 \%$ & 4 & $2 \%$ \\
know & 0 & & & & & &
\end{tabular}

Question: Are you aware of the fact that there are Type-A and Type- B problems in real life?

\subsubsection{Curriculum and Type-A problems}

Table 2 shows the summary of responses regarding the perceived view of what constitutes the current curriculum in mathematics. A total of 194 participants (80\%) expressed the view that most of the problems studied at school are Type-A problems. A total of 21 participants (9\%) expressed the view that Type-A problems do not constitute a majority of the problems studied at school. Twenty six participants (11\%) answered that they did not know.

Table 2. Curriculum and Type-A problems

\begin{tabular}{lrlllllllll}
\hline Option & \multicolumn{1}{c}{ EHU-1 } & \multicolumn{2}{c}{ UA } & \multicolumn{2}{c}{ UEX } & \multicolumn{2}{c}{ EHU-2 } & \multicolumn{2}{c}{ Total } \\
\hline Yes & 19 & $90 \%$ & 67 & $92 \%$ & 99 & $72 \%$ & 9 & $100 \%$ & 194 & $80 \%$ \\
No & 1 & $5 \%$ & 0 & $0 \%$ & 20 & $14 \%$ & 0 & $0 \%$ & 21 & $9 \%$ \\
I don't & 1 & $5 \%$ & 6 & $8 \%$ & 19 & $14 \%$ & 0 & $0 \%$ & 26 & $11 \%$ \\
know & 1 & & & & & & & & &
\end{tabular}

Question: Are you aware of the fact that most problems in the school's curriculum are Type-A problems?

\subsubsection{Life and Type-B problems}

Table 3 shows the opinion of participants on the type of problems that are prevalent in everyday life. A total of 152 participants (63\%) expressed the view that Type-B problems are predominant in daily life, while a total of 18 participants (7\%) were of the opinion that the prevalent problems were those categorizes as Type-A. A total of 72 participants (30\%) gave equal value to the role played by Type-A and Type-B problems in life.

Table 3. Life and Type-B problems

\begin{tabular}{lrrrrrrrrrr}
\hline Option & \multicolumn{1}{c}{ EHU-1 } & \multicolumn{2}{c}{ UA } & \multicolumn{2}{c}{ UEX } & EHU-2 & \multicolumn{2}{c}{ Total } \\
\hline Type-A & 5 & $24 \%$ & 1 & $1 \%$ & 11 & $8 \%$ & 1 & $11 \%$ & 18 & $7 \%$ \\
Type-B & 11 & $52 \%$ & 64 & $88 \%$ & 69 & $50 \%$ & 8 & $89 \%$ & 152 & $63 \%$ \\
Type-A and & 5 & $24 \%$ & 8 & $11 \%$ & 59 & $42 \%$ & 0 & $0 \%$ & 72 & $30 \%$ \\
Type-B & & & & & & & & & &
\end{tabular}

Question: In your opinion, the more prevailing problems in real life are:

\subsubsection{Experimenting with Type-B problems}

Table 4 shows the views of participants regarding experimentation with problems Type-B, and how it may improve the abilities to solve everyday problems. A total of 228 participants (94\%) believed that practicing with Type-B problems helped develop the skills needed to solve daily problems. A total of 5 participants (2\%) believed that this was not the case.

Table 4. Experimenting with Type-B problems

\begin{tabular}{|c|c|c|c|c|c|c|c|c|c|c|}
\hline Option & \multicolumn{2}{|c|}{ EHU-1 } & \multicolumn{2}{|c|}{ UA } & \multicolumn{2}{|c|}{ UEX } & \multicolumn{2}{|c|}{ EHU-2 } & \multicolumn{2}{|c|}{ Total } \\
\hline Yes & 20 & $95 \%$ & 73 & $100 \%$ & 127 & $91 \%$ & 8 & $89 \%$ & 228 & $94 \%$ \\
\hline No & 1 & $5 \%$ & 0 & $0 \%$ & 3 & $2 \%$ & 1 & $11 \%$ & 5 & $2 \%$ \\
\hline $\begin{array}{l}\text { I don't } \\
\text { know }\end{array}$ & 0 & $0 \%$ & 0 & $0 \%$ & 9 & $6 \%$ & 0 & $0 \%$ & 9 & $4 \%$ \\
\hline
\end{tabular}

Question: Do you believe that experimenting with Type-B problems develops the ability to solve 'real life problems and situations'?

\subsubsection{Solving New Problems through practice with Type-B problems}

Table 5 shows the views of participants on the implications of experimenting with Type-B problems to develop skills that can help solve new types of problems: problems that will appear in future new areas and that are still unknown. A total of 207 participants (86\%) believed that working and experimenting with Type-B problems developed skills that would allow students to solve new problems in the future. A total of 3 participants (1\%) thought that this was not the case. Thirty one participants (13\%) answered that they did not know.

Table 5. Solving New Problems through practice with Type-B problems

\begin{tabular}{|c|c|c|c|c|c|c|c|c|c|c|}
\hline \multirow{2}{*}{$\frac{\text { Option }}{\text { Yes }}$} & \multicolumn{2}{|c|}{ EHU-1 } & \multicolumn{2}{|c|}{ UA } & \multicolumn{2}{|c|}{ UEX } & \multicolumn{2}{|c|}{ EHU-2 } & \multicolumn{2}{|c|}{ Total } \\
\hline & 17 & $81 \%$ & 63 & $88 \%$ & 119 & $86 \%$ & 8 & $89 \%$ & 207 & $86 \%$ \\
\hline No & 0 & $0 \%$ & 1 & $1 \%$ & 2 & $1 \%$ & 0 & $0 \%$ & 3 & $1 \%$ \\
\hline $\begin{array}{l}\text { I don't } \\
\text { know }\end{array}$ & 4 & $19 \%$ & 8 & $11 \%$ & 18 & $13 \%$ & 1 & $11 \%$ & 31 & $13 \%$ \\
\hline
\end{tabular}

Question: Do you believe that experimenting with Type-B problems develops the ability to solve problems in new areas that will appear in the future, and that are still unknown? 


\subsubsection{To Study Type-B problems or not}

Table 6 shows the opinion of the participants on whether schoolage students should be trained in the field of Type-B problems. A total of 227 participants (95\%) expressed the view that students should be taught to solve Type-B problems. A total of 7 participants (3\%) believed that they should not.

Table 6. To Study Type-B problems or not

\begin{tabular}{|c|c|c|c|c|c|c|c|c|c|c|}
\hline Option & \multicolumn{2}{|c|}{ EHU-1 } & \multicolumn{2}{|c|}{ UA } & \multicolumn{2}{|c|}{ UEX } & \multicolumn{2}{|c|}{ EHU-2 } & \multicolumn{2}{|c|}{ Total } \\
\hline Yes & 16 & $84 \%$ & 72 & $100 \%$ & 132 & $95 \%$ & 7 & $78 \%$ & 227 & $95 \%$ \\
\hline No & 2 & $11 \%$ & 0 & $0 \%$ & 3 & $2 \%$ & 2 & $22 \%$ & 7 & $3 \%$ \\
\hline $\begin{array}{l}\text { I don't } \\
\text { know } \\
\end{array}$ & 1 & $5 \%$ & 0 & $0 \%$ & 4 & $3 \%$ & 0 & $0 \%$ & 5 & $2 \%$ \\
\hline
\end{tabular}

Question: Do you think that it is advisable to teach students to solve Type-B problems?

\subsubsection{Curriculum and Type-B problems}

Table 7 shows the opinion of participants on whether the current curriculum includes the study of Type-B problems. A total of 131 participants (54\%) expressed the opinion that this type of problems was not part of today's curriculum. A total of 63 participants (26\%) believed that the current curriculum already includes the study of Type-B problems. Forty seven participants (20\%) answered that they did not know.

Table 7. Curriculum and Type-B problems

\begin{tabular}{lcccccccccc}
\hline Option & \multicolumn{1}{c}{ EHU-1 } & \multicolumn{2}{c}{ UA } & \multicolumn{2}{c}{ UEX } & \multicolumn{2}{c}{ EHU-2 } & \multicolumn{2}{c}{ Total } \\
\hline Yes & 8 & $38 \%$ & 9 & $12 \%$ & 45 & $33 \%$ & 1 & $11 \%$ & 63 & $26 \%$ \\
No & 10 & $48 \%$ & 58 & $79 \%$ & 56 & $41 \%$ & 7 & $78 \%$ & 131 & $54 \%$ \\
$\begin{array}{l}\text { I don't } \\
\text { know }\end{array}$ & 3 & $14 \%$ & 6 & $8 \%$ & 37 & $27 \%$ & 1 & $11 \%$ & 47 & $20 \%$ \\
\hline
\end{tabular}

Question: Do you believe that Type-B problems are included in today's school's curriculum?

\subsubsection{Scratch/Snap and Type-B problems}

Table 8 shows the opinion of participants on whether the study of Type-B problems could be enhanced by using programming environments such as Scratch or Snap. A total of 196 participants (82\%) believed that programming environments such as Scratch or Snap could be used to teach students how to solve Type-B problems. A total of 15 participants (6\%) believed that these programming environments did not provide the means to do so. Twenty seven participants (11\%) answered that they did not know.

Table 8. Curriculum and Type-B problems

\begin{tabular}{lrlllrlllll}
\hline Option & \multicolumn{1}{c}{ EHU-1 } & \multicolumn{2}{c}{ UA } & \multicolumn{2}{c}{ UEX } & \multicolumn{2}{c}{ EHU-2 } & \multicolumn{2}{c}{ Total } \\
\hline Yes & 19 & $90 \%$ & 61 & $85 \%$ & 107 & $79 \%$ & 9 & $100 \%$ & 196 & $82 \%$ \\
No & 2 & $10 \%$ & 3 & $4 \%$ & 10 & $7 \%$ & 0 & $0 \%$ & 15 & $6 \%$ \\
I don't & 0 & $0 \%$ & 8 & $11 \%$ & 19 & $14 \%$ & 0 & $0 \%$ & 27 & $11 \%$ \\
know & 0 & & & & & & & &
\end{tabular}

Question: Do you believe that programing environments such as Scratch/Snap are helpful in students' preparation to solve Type-B problems?

\subsubsection{Scratch/Snap in the Curriculum}

Table 9 shows the preferred courses in the curriculum where programming environments such as Scratch or Snap should be integrated. A total of 126 participants (52\%) selected a Technology class. Fifty-one participants (21\%) chose to include these programming environments in the context of a mathematics class, while 49 (20\%) participants opted for the creation of a new course especially designed to study these topics. Twelve participants (5\%) preferred these activities to take place outside the regular class day, as an extracurricular activity, and 4 participants (2\%) thought that these studies should not be included at all.

Table 9. Scratch/Snap in the Curriculum

\begin{tabular}{|c|c|c|c|c|c|c|c|c|c|c|}
\hline Option & \multicolumn{2}{|c|}{ EHU-1 } & \multicolumn{2}{|c|}{ UA } & \multicolumn{2}{|c|}{ UEX } & \multicolumn{2}{|c|}{ EHU-2 } & \multicolumn{2}{|c|}{ Total } \\
\hline $\begin{array}{l}\text { Technology } \\
\text { Course }\end{array}$ & 9 & $43 \%$ & 28 & $38 \%$ & 88 & $63 \%$ & 1 & $11 \%$ & 126 & $52 \%$ \\
\hline Math Course & 8 & $38 \%$ & 22 & $30 \%$ & 14 & $10 \%$ & 7 & $78 \%$ & 51 & $21 \%$ \\
\hline New Course & 3 & $14 \%$ & 19 & $26 \%$ & 26 & $19 \%$ & 1 & $11 \%$ & 49 & $20 \%$ \\
\hline $\begin{array}{l}\text { After School } \\
\text { Activities }\end{array}$ & 0 & $0 \%$ & 3 & $4 \%$ & 9 & $6 \%$ & 0 & $0 \%$ & 12 & $5 \%$ \\
\hline $\begin{array}{l}\text { Do Not } \\
\text { Introduce }\end{array}$ & 1 & $5 \%$ & 1 & $1 \%$ & 2 & $1 \%$ & 0 & $0 \%$ & 4 & $2 \%$ \\
\hline
\end{tabular}

Question: Where do you think programming environments such as Scratch/Snap should be integrated into the curriculum?

\subsection{Comments \& Interviews}

\subsubsection{Students' comments}

The final survey included an optional field where the participating students could include their comments and opinions regarding the workshop. Most comments were of the type "a very interesting workshop" with added descriptions such as "innovator, useful, effective, enriching, and motivating.”

Many of the comments synthesized and summarized the proposed goal of the workshop in short phrases: "We liked this workshop very much because we learned that there are different types of problems, and also how to analyze them. We believe that Scratch is a very interesting program." "The Scratch software is very interesting. It made us reflect on the different types of problems. Thank you very much." "I think that it was a very interesting and dynamic class, where we learned that not only Type-A problems but also Type-B problems exist in real life, and that their study in this class will prove very helpful in the future. I also think that Scratch is very interesting." "I think this workshop was very interesting because we learned how to solve different types of problems."

Other comments reveal a globalizing vision on problem resolution: "We liked this workshop because we used to consider as problems only those with a mathematical perspective and now we have discovered the existence of other types as well as their characteristics and difficulties." "I found this workshop very interesting since it allowed us to find out that there are different types of problems, not only math problems.”

\subsubsection{Interviews with teachers}

The different course instructors were additionally interviewed at the end of each experience so as to find out their opinion on the effect of the workshop in the overall course as well as among students. The teachers of all four campuses pointed out that the experience had been very interesting and they expressed their intention of repeating the experience during the subsequent academic year.

The EHU-2 instructor summarized her experience as follows: "The general evaluation of this experience is highly positive. Students have valued the pedagogical approach and the didactic resources used, which will allow them to use those resources in a wide variety of teaching and learning situations. They have acquired information, guidelines for later learning, development 
of skills, motivation, interest, and also the creation of a favorable environment for communication in numerous areas, and particularly in mathematics, of all the processes related to Problem Solving. This is extremely important for later courses in our opinion. The length of the workshop perhaps should be increased in future editions."

In turn, the UEX instructor described her experience like this: "The experience was very satisfying and highly valued by students. It allowed them to learn about the use of Scratch as a creative tool for the generation of activities and didactic materials clearly useful for learning-teaching situations inside their Primary Education classroom. Likewise, this experience allowed them to reflect about the types of mathematical and real problems that they will encounter in everyday life, and analyze possible solutions when facing these situations in the classroom, creating an environment that is both stimulating and socializing (when implementing these tasks in small groups), and learn from the exchange and debate with other colleagues. Finally, I have had the chance to know about MIT's Scratch project and the development of the team AprendiendoScratch, which is successfully bringing this tool and their vision on how to work with daily life problems using a tool that is accessible, friendly and fun to use."

\section{DISCUSSION AND CONCLUSIONS}

We have presented a study implemented in collaboration with Schools of Education based in three universities (4 campuses in total) where a workshop was offered to students enrolled in the first or second year of these Schools, in order to introduce a space for reflection on the topic of mathematics education. The main objective of the workshop was to offer a working tool to help achieve a deeper understanding of problem-solving processes, and in particular in the area of mathematics within the framework of today's educational systems.

The surveys in this study revealed that according to most participants: (i) the K-12 Mathematics curricula are designed to teach students exclusively the resolution of Type-A problems, (ii) real life Math problems respond to a paradigm of Type-B problems, and (iii) the current Math curriculum should be modified to include this new paradigm.

Question one in the survey shows that an overwhelming majority (95\%) of participants believes that both Type-A and Type-B problems are confronted in real life experiences. These problems are very different in nature, in complexity, and in terms of the mental processes required to solve them. This finding indicates that participants clearly identify the problems encountered during our daily activities, and that these problems can be immediately categorized into two different groups.

Question two in the survey shows that an overwhelming majority (80\%) of participants believe that the current curriculum in the area of mathematics focuses its attention almost exclusively on Type-A problems. Even though there are theories which try to justify why this is the case, this is a fundamental conclusion that should inform the dialog when analyzing the state of the current curriculum, the needs of society, and the new proposed changes to the curriculum.

The third survey question explores the finding of the first question in greater depth. Both Type-A and Type-B problems exist in real life, but two thirds of participants (63\%) believe that Type-B problems are predominant in real life, while only one third (30\%) believe that both types are equally prevalent. This finding indicates that Type-B problems not only exist but also represent the majority of challenges that citizens have to face day in day out.

As for the fourth question in the survey, it shows that experimenting with Type-B problems develops the abilities to solve real life problems in the opinion of a vast majority of participants (94\%). This finding suggests exploring new pedagogical approaches to learning that can prepare our students for their lives after school. Experimenting with Type-B problems in appropriate environments, such as Scratch or Snap, develops skills suited to the tasks developed in these cases: iteration, interfacing with the world, progressive optimization, object-oriented thinking, etc.

The responses to the fifth survey question indicate that a vast majority of participants (86\%) think that experimenting with Type-B problems develops abilities to solve new problems. This is an intrinsic property of this method of experimentation and may have implications in the adoption of new pedagogical paradigms where solving new problems stands out as a high priority.

Question six of the survey shows that a vast majority of participants (95\%) believe that it is important to teach our students the capacities to solve Type-B problems. In conjunction with the finding from survey question number seven, where a small majority (54\%) think that Type-B problems are not included in the current curriculum (and only 26\% think they are), this finding suggests a fundamental area of dialog regarding the nature and content of the curriculum, as well as the need and direction of change.

The results of survey question number eight indicate that a large proportion of participants (82\%) view programming environments such as Scratch or Snap as appropriate tools to help integrate Type-B problems into the classroom.

The results derived from survey question number nine show that, according to participants, the integration of environments such as Scratch or Snap should occur within current Technology courses (52\%), current Math courses (21\%) or in a new course specifically created for that purpose (20\%).

The results obtained in this study reveal that most participants were able to reach clear conclusions on the content of the Math curriculum. This fact has two essential implications: the first one is that Type-A and Type-B problems respond to different and easily recognizable paradigms, and that participants had no difficulty identifying them; the second implication is that the experiences and exercises implemented during the workshop provided the cognitive resources that allowed participants to answer these questions clearly and knowledgeably.

Those research groups interested in replicating the experiences can obtain the didactic materials used in the workshops by contacting the authors.

The next phases of this project include a set of new workshops where specific areas of Type-B problems are presented and a set of strategies are described to develop new curricula. The goal of these workshops is to familiarize participants with the curricular relevance of these areas and their mathematical content, and to train them in the development of new curricular activities, and their integration into the classroom. These specific areas include: Differential vector geometry; Object-oriented three-dimensional geometry; Cybernetics -self regulated systems; Probability thinking; Dynamic of bodies with discrete calculus. 


\section{REFERENCES}

ACT (2013). American College Testing. Retrieved from https://www.act.org

Ariely, D. (2009). Predictably Irrational. New York, NY. HarperCollins

Bälter, O., Enström, E., \& Klingenberg, B. (2013). The effect of short formative diagnostic web quizzes with minimal feedback. Comput. Educ. 60, 1 (January 2013), 234-242. doi: 10.1016/j.compedu.2012.08.014

Basogain, X., Olabe, M. A., Olabe, J. C., Maiz, I., \& Castaño, C. (2012). Mathematics Education through Programming Languages. 21st Annual World Congress on Learning Disabilities, 553-559.

Becker, K. A. (2003). History of the Stanford-Binet Intelligence scales: Content and psychometrics. Stanford-Binet Intelligence Scales, Fifth Edition Assessment Service Bulletin, 1.

Binet, A. \& Simon, Th. (1916). The development of intelligence in children: The Binet-Simon Scale. Baltimore: Williams \& Wilkins company. doi: 10.1037/11069-000

Carpenter, P. A., Just, M. A. \& Shell, P. (1990). What One Intelligence Test Measures: A Theoretical Account of the Processing in the Raven Progressive Matrices Test. Psychological Review, 73 (3), 404431. doi: 10.1037/0033-295X.97.3.404

Cattell, R. B. (1963). Theory of fluid and crystallized intelligence: A critical experiment. Journal of Educational Psychology, 54, 1-22. doi: $10.1037 / \mathrm{h} 0046743$

Collins, A. \& Halverson, R. (2009). Rethinking Education in the Age of Technology: The Digital Revolution and the Schools. New York: Teachers College Press.

Disessa, A. (2000). Changing minds: Computers, learning, and literacy. Cambridge: MIT Press.

Fiske, S. T., Gilbert, D. T., \& Lindzey, G. (Eds.) (2010). The handbook of social psychology (5th edition). New York: Wiley.

Forbes, A. R. (1964). An item analysis of the advanced matrices. British Journal of Educational Psychology, 34, 1-14. doi: 10.1111/j.20448279.1964.tb00632.x

Jensen, A. R. (1987). The g beyond factor analysis. In R. R. Ronning, J. A. Glover, J. C. Conoley, \& J. C. Witt (eds.). The influence of cognitive psychology on testing (pp. 87-142). Hillsdale: NJ: Erlbaum.

Kahneman, D. (2003). Maps of Bounded Rationality: Psychology for Behavioral Economics. The American Economic Review, 93 (5), 1449-1475. doi: 10.1257/000282803322655392

Maloney, J., Resnick, M., Rusk, N., Silverman, B., \& Eastmond, E. (2010). The Scratch Programming Language and Environment. ACM Transactions on Computing Education, 10 (4), 15 pp. doi: 10.1145/1868358.1868363

Marshalek, B., Lohman, D. F., \& Snow, R. E. (1983). The complexity continuum in the radix of hierarchical models of intelligence. Intelligence, 7, 107-127. doi: 10.1016/0160-2896(83)90023-5

National Research Council (2010). Committee for the Workshops on Computational Thinking: Report of a workshop on the scope and nature of computational thinking. Washington, DC: National Academies Press.

National Research Council (2011). Committee for the Workshops on Computational Thinking: Report of a workshop of pedagogical aspects of computational thinking. Washington, DC: National Academies Press.

Papert, S. (1980). Mindstorms: Children, computers, and powerful ideas. New York: Basic Books.

Papert, S. (1991). Situating constructionism. In I. Harel, \& S. Papert (Eds.), Constructionism. 1-11. Norwood, NJ: Ablex.

Pisa (2009). PISA 2009 key findings. OECD Programme for International Student Assessment (PISA). Retrieved from http://www.oecd.org/pisa/pisaproducts/pisa2009/pisa2009keyfinding s.htm

Raven, J. C. (1962). Advanced Progressive Matrices, Set II. London: H. K. Lewis.

Royal Society. (2012). Shut down or restart: The way forward for computing in UK schools. Retrieved from royalsociety.org/education/policy/computing-in-schools

SAT (2013). Scholastic Assessment Test. College Board. Retrieved from http://sat.collegeboard.org/

Schwartz, B. (2005). The Paradox of Choice: Why More Is Less. New York: Harper Collins.

Scratch (2013). Lifelong Kindergarten Group at the MIT Media Lab. Retrieved from http://scratch.mit.edu/

Snap (2013). Mönig, J., \& Harvey, B. University of California at Berkeley. Retrieved from http://byob.berkeley.edu/

Snow, R. E., Kyllonen, P. C., \& Marshalek, B. (1984). The topography of ability and learning correlations. In R. J. Sternberg (Ed.),
Advances in the Psychology of Human Intelligence, Volume 2, (47103). Hillsdale, NJ: Lawrence Erlbaum Associates.

Taylor, K., \& Rohrer, D. (2010). The effects of interleaved practice. Applied Cognitive Psychology, 24, 837-848. doi: 10.1002/acp.1598

Utting, I., Cooper, S., Kolling, M., Maloney, J., \& Resnick, M. (2010). Alice, greenfoot and scratch-A discussion. ACM Transactions on Computing Education, 10 (4): 11 pp. doi: 10.1145/1868358.1868364

Wechsler, D. (1939). Wechsler-Bellevue intelligence scale. New York: The Psychological Corporation.

Wechsler, D. (2005). Wechsler Individual Achievement Test 2nd Edition (WIAT II). London: The Psychological Corporation.

Wing, J. (2006). Computational thinking. Communications of the ACM, 49 (3), 33-36. doi: 10.1145/1118178.1118215

\section{ACKNOWLEDGMENTS}

This research has been supported in part by a Research Development Grant of the University Basque System (2010-15 IT863-13), Department of Education, Universities and Research - Basque Government. The authors would like to express their gratitude for the participation and collaboration of the faculty and students of the University of the Basque Country, the University of Alicante, and the University of Extremadura, who have made this work possible. 